\title{
The Central Roles of Information in Health Justice, Part 1: Toward a New Field of Consumer Health Information Justice
}

Beth St. Jean, University of Maryland, College Park, USA

Gagan Jindal, University of Maryland, College Park, USA

Yuting Liao, University of Maryland, College Park, USA

Paul T. Jaeger, University of Maryland, College Park, USA

Keywords: consumer health information behavior; consumer health information justice; health disparities; health justice; health literacy; information access

Publication Type: introductory article

\section{Introduction}

"Of all the forms of inequality, injustice in health is the most shocking and the most inhuman because it often results in physical death."

Dr. Martin Luther King, Jr., 1966 (Galarneau, 2018)

\begin{abstract}
A Ithough more than 50 years have passed since Dr. Martin Luther King, Jr. spoke these words, health justice-the recognition and fulfillment of the moral entitlement of every individual to a sufficient and equitable capability to be healthy (Venkatapuram, 2011)remains just a distant goal, both in the U.S. and around the globe. Individuals and communities who experience various forms of social injustice, such as poverty, inadequate education, and insufficient health insurance, along with the limited access to resources and opportunities that frequently accompany these injustices, face higher rates of illness, injury and premature death (Levy \& Sidel, 2013). However, information professionals and information, as both resources in and of themselves and as stepping stones that enable people to become aware of and able to take advantage of opportunities, have tremendous potential to play fundamental roles in contributing to much-needed progress toward health justice. Information professionals and information are central to ensuring that all people have access to the resources and opportunities they need in order to be able to live a long and healthy life.
\end{abstract}

Health disparities and health injustice are widespread both between and within countries throughout the world (Lee et al., 2015; Ruger, 2004; World Health Organization [WHO], 2011). Furthermore, there is some evidence that, rather than making progress toward equity and health justice, health injustice only continues to become more widespread across our nation. One way in which we may gauge health equity (or health disparities) in a society is to look at differences in life expectancy. Research has consistently shown that U.S. residents who are wealthier, better educated, and white live 10-15 years longer, on average. For example, one study (Chetty et al., 2016) found that 40 -year-old men in the top 1\% income bracket have a life expectancy 15 years greater than 40 -year-old men in the bottom $1 \%$ income bracket ( $87.3 \mathrm{vs.} 72.7$ years). The pattern is similar for 40 -year-old women-those in the highest $1 \%$ income bracket have a life expectancy 10 years greater than those in the bottom $1 \%$ income bracket ( 88.9 vs. 78.8 years). Another study (Olshansky et al., 2012) identified analogous differences in life expectancy based on people's

The International Journal of Information, Diversity, \& Inclusion, 3(3), 2019

ISSN 2574-3430, jps.library.utoronto.ca/index.php/ijidi/index

DOI: $10.33137 /$ ijidi.v3i3.32961 
educational attainment and race, finding that white Americans with at least 16 years of education by the time they were 25 had a life expectancy of 10.3 (for females) to 14.2 (for males) years greater than African Americans with less than 12 years of education by this age. Most concerningly, both Chetty et al. (2016) and Olshansky et al. (2012) found that these gaps in life expectancy have only continued to widen over time. These disparities in life expectancy provide very clear evidence of health injustice, and such health inequities have been found to be largely caused by the social determinants of health; that is, "the conditions in which persons are born, grow, live, work and age" (WHO, 2011, p. 2). These conditions certainly include health care systems (Lee et al., 2015); however, they extend far beyond, encompassing all aspects of an individual's life. Thus, in order to achieve social justice with respect to health, our focus needs to be on the much broader "right to health and human flourishing" (or, more specifically, the right to "health capabilities," which includes, at a minimum, the abilities to avoid premature death and preventable disease), rather than on the much narrower "right to healthcare" (Ruger, 2004, 2006a, 2006b).

The capabilities approach to health justice (Venkatapuram, 2011) is an adaptation of Indian economist and philosopher Amartya Sen's (1993) broader "capability approach to well-being and advantage," which posits that the primary criterion for evaluating an individual's well-being is "his or her actual ability to achieve various valuable functionings as a part of living" (p. 30). Adapting Sen's capability approach for the health context, Venkatapuram (2011) defines health justice as a "moral right to the capability to be healthy" (p. 19), specifying that this capability must be both sufficient and equitable. Venkatapuram points out that this entitlement to the capability to be healthy is not to specific health outcomes (as this would be impossible), but to the social bases of the capability to be healthy. Describing how the capability to be healthy relies on both individual determinants (behaviors as well as biological endowments and needs that change across one's life stages) and societal determinants (physical environment and social conditions). Venkatapuram emphasizes that every individual has a "moral claim to the practically possible and permissible social interventions into those four determinants in order to produce a [capability to be healthy] that is commensurate with equal human dignity in the modern world" (p. 19). Venkatapuram also emphasizes that we have social obligations to, at the very minimum, not constrain an individual's capability to be healthy, but also to do what we are able (given our own individual abilities and powers) to address the consequences of any past harms to an individual's capability to be healthy and to protect, sustain, promote, and restore every individual's capability to be healthy.

Going well beyond the WHO's (1946) definition of health as "a state of complete physical, mental, and social well-being and not merely the absence of disease or infirmity" (p. 1), Venkatapuram (2011) draws on Aristotle's concept of eudaimonia to conceptualize health as an individual's abilities that enable them to flourish. He further specifies that the capability to be healthy is a meta-capability that comprises the various abilities one needs to do so. Applying the capabilities approach specifically to the lives of women in developing countries, Nussbaum (2000) specifies 10 central human capabilities:

1. Being able to live a normal lifespan.

2. Having good health.

3. Being able to maintain bodily integrity.

4. Being able to use one's senses, imagine, think, and reason (and to do so in an informed way).

5. Having emotions and emotional attachments.

The International Journal of Information, Diversity, \& Inclusion, 3(3), 2019

ISSN 2574-3430, jps.library.utoronto.ca/index.php/ijidi/index

DOI: $10.33137 /$ ijidi.v3i3.32961 
6. Being able to "form a conception of the good" (p. 79) and plan one's life.

7. Having social affiliations that are meaningful and respectful.

8. Having concern for other species.

9. Being able to laugh, play, and enjoy oneself.

10. Having control over one's material \& political environment.

Nussbaum emphasizes that society cannot provide these capabilities themselves, only the social bases for each capability. She further points out that, under the capabilities approach, society must "make up for differences in starting point that are caused by natural endowment or by power" (p. 81).

To have a sufficient and equitable capability to be healthy, one needs fair and equitable access to a wide array of resources and opportunities, particularly information (as Nussbaum [2000] specifically calls out in her fourth central human capability). Predating and fundamentally underpinning Dr. Martin Luther King, Jr.'s 1966 remarks, the WHO's 1946 Constitution states, "The enjoyment of the highest attainable standard of health is one of the fundamental rights of every human being without distinction of race, religion, political belief, economic or social condition" (p. 1). The WHO (2017) specifically mentions information as one of the "underlying determinants of health," stating: "Achieving the right to health is both central to, and dependent upon, the realisation of other human rights, to food, housing, work, education, information, and participation." Similarly, General Comment No. 14 ("The right to the highest attainable standard of health") of the United Nations Committee on Economic, Social and Cultural Rights (2000) outlined four essential elements of the right to health, including: (1) availability of health and health care facilities, goods, and services; (2) accessibility; (3) acceptability of health facilities, goods, and services, particularly in terms of being culturally respectful and sensitive to people's needs; and (4) quality of health facilities, goods, and services. The Committee further breaks down accessibility into four dimensions: (a) non-discrimination; (b) physical accessibility; (c) economic accessibility; and (d) information accessibility. Regarding the latter, the Committee specifies that information accessibility includes "the right to seek, receive and impart information and ideas concerning health issues" (p. 4), and goes on to emphasize, "this General Comment gives particular emphasis to access to information because of the special importance of this issue in relation to health" (p. 18). Information is very clearly one of the central resources to which one needs both physical and intellectual access in order to have a sufficient and equitable capability to be healthy.

Central to the rampant health inequities and the lack of health justice in the U.S. are interrelated disparities in access to health information and limitations in health literacy. Health literacy is "the degree to which individuals have the capacity to obtain, process, and understand basic health information and services needed to make appropriate health care decisions" (Ratzan \& Parker, 2000). Nearly $90 \%$ of adults in the U.S. have a below-proficient level of health literacy (Kutner, Greenberg, Jin, \& Paulsen, 2006). Disadvantaged populations, including those who have lower incomes, are less well educated, are older, belong to a minority population, or who are immigrants, are much more likely to have limited health literacy (NN/LM, n.d.). Limited health literacy levels, in turn, have been found to strongly correlate with reduced likelihood of getting preventative health care, poorer self-reported health status, higher rates of hospitalization, greater use of emergency services, and poorer health outcomes (Institute of Medicine, 2004). For example, Schillinger et al. (2002) point specifically to poor health literacy as a likely contributor to the greater diabetes-related problems experienced by people with type 2 diabetes who are disadvantaged. Another study (St. Jean, Jindal, \& Liao, 2017; Liao, Jindal, \& St. Jean,

The International Journal of Information, Diversity, \& Inclusion, 3(3), 2019

ISSN 2574-3430, jps.library.utoronto.ca/index.php/ijidi/index

DOI: $10.33137 /$ ijidi.v3i3.32961 
2018) found that the same disadvantaged populations who are more likely to have limited health literacy are also more likely to prefer to avoid health-related information. Underscoring the central tie between low health literacy and health disparities, as well as the fundamental roles that can be played by information in creating or reducing health inequities and health injustice, Weiss (2007) reports that low health literacy has been found to be a stronger predictor of one's health than one's age, race, educational attainment, employment status, and income.

This special issue is Part 1 of a pair of special issues of The International Journal of Information, Diversity, \& Inclusion that focus on this important topic of health justice, particularly focusing on the various types of information-related factors and processes that are central to the achievement of health justice, such as information access, information needs, health literacy, information provision, and consumer health information behavior (CHIB). As the consumer health movement has accelerated over the past few decades and patients are increasingly taking responsibility for their own health, recognition of the central role of information access and CHIB in influencing people's health trajectories and outcomes has steadily grown. CHIB, which encompasses people's health-related information needs as well as the activities in which they engage (or not) in order to find, assess, manage, and use information to maintain or improve their health, can have profound consequences for one's health trajectory, quality of life, and health outcomes. As Johnson (2014) explains, "The scope and nature of the information on which to base [health-related] judgments, the repertoire of alternative courses of action known to the searcher, and ultimately the action taken are affected by individuals' information-seeking behaviors" (p. 709). The decisions an individual makes and the actions that they do or do not take fundamentally rely on their awareness and access to information sources and their healthrelated information behaviors. In turn, their decisions and actions (or inaction) influence their health trajectories and their ultimate health outcomes, profoundly shaping their experiences of health (in)justice.

\section{The Current IJIDI Special Issue}

This issue brings together researchers who focus specifically on health justice and/or social justice within a health-related context. The central focus is on the various types of informationrelated factors and processes that are central to the achievement of health justice, such as the health information needs of disadvantaged and/or marginalized populations; their health information seeking and use practices; and the provision of health information to these populations. Submissions examining closely related issues, such as information access, health literacy, health communication, use and usability of consumer health information technology, patient experience, stigma, information poverty, information avoidance and so forth were also welcomed. Our impetus for this special issue was that much of the work in this space is currently scattered across multiple disciplines and many different journals within each of these disciplines. It is hoped that this special issue provides an opportunity for readers and researchers to come together in one space to learn about and share their work on this very important topic.

The three articles and two special section papers that comprise this special issue focus on a wide range of factors that directly relate to health justice, including information access issues, equity concerns, health disparities, and health-related public library programs to improve health outcomes among disadvantaged populations.

The first paper focuses on the potential roles of unfulfilled information needs and limited health literacy levels in individuals' experiences of health injustice. In 'The Information Needs of

The International Journal of Information, Diversity, \& Inclusion, 3(3), 2019

ISSN 2574-3430, jps.library.utoronto.ca/index.php/ijidi/index

DOI: $10.33137 /$ ijidi.v3i3.32961 
Individuals Affected by Harmful Gambling in Ireland," Crystal Fulton describes the help- and information-seeking behaviors of recovering gamblers in Ireland. Drawing on in-depth interviews with a range of stakeholders, including recovering gamblers, their family members and friends, and addiction counselors who help people affected by harmful gambling, Fulton identified a range of barriers to gamblers' and their family members' help- and information-seeking, including perceptions of shame and stigma and the inaccessibility or non-existence of the information and help that they needed. Fulton's study participants called for increased regulation of gambling through national legislation; the development of resources and services for people harmed by (or at risk of harm from) gambling; and increased dialogue and education about gambling in order to raise public awareness of potential harm from gambling and to reduce shame and stigma around this issue.

The next article focuses individuals experiencing health (in)justice in the workplace. In "Work Experiences, Accommodations, and Information in the Context of Fibromyalgia: A Literature Review and Conceptual Synthesis," Annie T. Chen, Holly Carpenter, and Mary Grace Flaherty explore the literature focusing on the work experiences of fibromyalgia patients, the types of challenges they face in the workplace, and the types of work accommodations that can prove beneficial for them. Chen et al. provide a conceptual synthesis, identifying several gaps in the literature pertaining to the information needs and seeking of, and the information resources used by, fibromyalgia patients as they engage in workplace self-advocacy and strive to secure any needed work accommodations. In conclusion, Chen et al. call for additional research focusing on the information seeking behavior of fibromyalgia patients as they seek work accommodations, as well as the involvement of all concerned stakeholders (including employees, employers, and service providers) in the accommodations process.

The final article details the ways in which public health agencies work to promote health justice. "Scenarios of Health Engagement Experiences and Health Justice in Rural Libraries," written by Bharat Mehra, Everette Scott Sikes, and Vandana Singh, describes the health engagement experiences of 15 rural librarians in the Southern and Central Appalachian (SCA) region. Drawing on their semi-structured interviews with these librarians, Mehra et al. use scenarios as a health justice tool to counteract past unfair, marginalizing representations that paint the SCA rural belt in a deficit light. Taking instead a constructive asset recognition approach, the authors spotlight the SCA rural librarians' examples of their health activities in community engagement across 11 different domains. Librarians described offering a wide array of health-related programming, often in collaboration with various types of partners (e.g., government agencies, university extension services, hospitals, businesses, community organizations), including summer feeding programs, dental screening workshops, health information materials for particular population subgroups (such as teens, elderly, or Spanish-speakers), walking clubs, health fairs, baby care classes, aging with disability classes, domestic violence counseling, health insurance informational sessions, mental health kiosks, and so forth. Mehra et al. describe some of the challenges in community-engaged rural health, such as limited resource availability and lack of public awareness of these offerings. In conclusion, these authors highlight some of the important impacts of these library-led community-engaged health programs, including exponentially increasing attendance and community members who have improved health literacy skills and who are more empowered and better equipped to live active and healthy lives.

The two papers in the special section, entitled "Health Justice in Policy," offer examinations of health justice issues raised in the application of relevant policies. "Same Tricks, New Name: The IAAF's New 2018 Testosterone Regulation Policy for Female Athletes" by Anna Posbergh examines

The International Journal of Information, Diversity, \& Inclusion, 3(3), 2019

ISSN 2574-3430, jps.library.utoronto.ca/index.php/ijidi/index

DOI: $10.33137 /$ ijidi.v3i3.32961 
gender classification within professional athletics. Posbergh discusses the International Association of Athletics Federation's (IAAF) "eligibility regulations for female classification," making the case that this policy prioritizes scientific knowledge and discriminates against athletes whose gender identity does not fit within the socially constructed gender binary through its use of testosterone levels to define athletes as either male or female. Under this new regulation, an athlete is not permitted to compete against other women unless she is recognized by law as either female or intersex and unless she continuously maintains a blood testosterone level of less than five nanomoles per liter. Drawing on Foucault's (1978) concept of biopower, Posbergh argues that this policy is an attempt to regulate athletes' (particularly female athletes') bodies and that it contributes to the unjust and inequitable treatment of intersex athletes.

In "Creating a Culture of Equity: Building Awareness within the Montgomery County Department of Health and Human Services (MCDHHS)," Surbhi Sardana (Community Health Program Coordinator for MCDHHS) describes the design and implementation of a comprehensive workshop that aims to increase awareness and knowledge about equity among Department staff and enable them to treat their clients, customers, and colleagues more equitably. Sardana points out that the rosy health outcome statistics about Montgomery County, MD (a majority-minority, large urban/suburban county in Maryland) mask the barriers in access to health care and health disparities experienced by certain population groups in the county. The goal of the "Creating a Culture of Equity" workshop is to empower Department staff to work toward better and more equitable health outcomes for disadvantaged communities in the county. Sardana describes the impacts of this well-attended workshop, as well as a few of the challenges that have arisen. In conclusion, Sardana describes some of the Department's recent and next steps with regard to the workshop and the promotion of health justice in the County, including their plan to develop equity toolkits and trainings on hot topics, such as implicit bias.

\section{Moving Forward}

All of the papers in these two companion special issues will help to establish a firm foundation for an emerging area of consumer health information behavior research and information professional practice, which we term Consumer Health Information Justice (CHIJ). The potential to achieve health justice rests necessarily on a wide array of information-related factors. People certainly do not have a sufficient and equitable capability to live a long and healthy life if they are not aware of trustworthy sources of health information, if they lack access to such information, if they're unaware of or unable to articulate their health-related information needs, if they have limited health literacy, and so forth. People's information behaviors (which are fundamentally influenced by all of these underlying factors), encompassing their information seeking and information avoidance behaviors, their information use and their information nonuse and so forth, all play a central role in shaping people's potential and actual health trajectories, as well as their ultimate health outcomes. Thus, information-related factors play a fundamental role in whether, and to what extent, an individual will experience health injustice. Fortunately, nearly all of these information-related factors are malleable and we, as both individuals and information professionals, have an opportunity and a responsibility to help to shape these factors so as to optimize every individual's capability to be healthy and to flourish.

The concept of CHIJ is part of a growing recognition of information access as a central and foundational aspect of social justice. Social justice is based on the principles of fairness, respect, and equity for all members of a community (Sensoy \& Diangelo, 2012). As information and related

The International Journal of Information, Diversity, \& Inclusion, 3(3), 2019

ISSN 2574-3430, jps.library.utoronto.ca/index.php/ijidi/index

DOI: $10.33137 /$ ijidi.v3i3.32961 
technologies-and the necessary literacies to use them effectively-have become increasingly essential to education, employment, social interaction, and civic participation, information is increasingly understood as a key to social justice for both individuals and communities (Jaeger, Taylor, \& Gorham, 2015). The achievement of equality, however, requires more than finding a way to accomplish equal distribution of resources or opportunities, as different needs and social contexts may require greater interventions for certain groups to achieve equality (Cramme \& Diamond, 2009, Nieto, 2010). Information professionals, as the profession most knowledgeable and passionate about making information available and understandable, are finding ever-larger and more creative ways to employ information and technologies to promote social justice in their communities (Gorham, Taylor, \& Jaeger, 2016). In the overall health context, these activities range from health literacy courses to community health nurses being employed by public libraries.

Information professionals have very valuable and directly relevant expertise and experience that can be drawn upon to improve every individual's capability to be healthy, thereby enabling us to move much closer toward health justice. Drawing on the four essential elements of the right to health set forth by the United Nations Committee on Economic, Social and Cultural Rights (2000), we can work to increase the availability, accessibility, acceptability, and quality of health information for all individuals. We can do so both by directly improving people's access to trustworthy health-related information and by working with them to improve their health literacy skills so they are better able to find, understand, assess, manage, share, and make use of this information. In taking these steps, we can help to reduce the barriers that patients encounter, such as in their attempts to obtain healthcare coverage, find a trusted healthcare provider, and learning how to maintain and manage their health. Removing these barriers, in turn, will enable individuals to make better informed decisions around all aspects of their health. Individuals will be able to develop their own expertise and better work with their health care providers to make collaborative choices about their health and their care, taking into consideration their own preferences and priorities. In addition to strategies that involve working directly with individuals, we can also work to decrease health disparities by addressing deeply embedded structural and institutional barriers that can negatively impact vulnerable populations, constraining their capability to be healthy and their ability to flourish.

\section{References}

Chetty, R., Stepner, M., Abraham, S., Lin, S., Scuderi, B., Turner, N., Bergeron, A., Cutler, D. (2016). The association between income and life expectancy in the United States, 2001-2014. Journal of the American Medical Association, 315(16), 1750-1766. doi:10.1001/jama.2016.4226

Cramme, O., \& Diamond, P. (2009). Rethinking social justice in the global age. In O. Cramme \& P. Diamond (Eds.), Social justice in the global age (pp. 3-20). Cambridge, UK: Polity Press.

Foucault, M. (1978). The history of sexuality. New York, NY: Pantheon Books.

Galarneau, C. (2018). Getting King's words right. Journal of Health Care for the Poor and Underserved, 29(1), 5-8. https://doi.org/10.1353/hpu.2018.0001

The International Journal of Information, Diversity, \& Inclusion, 3(3), 2019

ISSN 2574-3430, jps.library.utoronto.ca/index.php/ijidi/index

DOI: $10.33137 /$ ijidi.v3i3.32961 
Gorham, U., Taylor, N. G., \& Jaeger, P. T. (Eds.). (2016). Perspectives on libraries as institutions of human rights and social justice. Bingley, UK: Emerald.

Institute of Medicine. (2004). Health literacy: A prescription to end confusion. Washington, DC: The National Academies Press.

Jaeger, P. T., Taylor, N. G., \& Gorham, U. (2015). Libraries, human rights, and social justice: Enabling access and promoting inclusion. Lanham, MD: Rowman \& Littlefield.

Johnson, J. D. (2014). Health-related information seeking: Is it worth it? Information Processing \& Management, 50(5), 708-717. https://doi.org/10.1016/j.ipm.2014.06.001

Kutner, M., Greenberg, E., Jin, Y., \& Paulsen C. (2006). The health literacy of America's adults: Results from the 2003 National Assessment of Adult Literacy (NCES 2006-483). Washington, DC: U.S. Department of Education, National Center for Education Statistics.

Lee, H., Kim, S., DeMarco, R., Aronowitz, T., Mtengezo, J., Kang, Y., \& Fitzpatrick, J. J. (2015). Recognizing global disparities in health and in health transitions in the 21st century: What can nurses do? Applied Nursing Research, 28(1), 60-65. https://doi.org/10.1016/j.apnr.2014.09.004

Levy, B. S., \& Sidel, V. W. (2013). Social injustice and public health (2nd ed.). New York, NY: Oxford University Press.

Liao, Y., Jindal, G., \& St. Jean, B. (2018). The role of self-efficacy in cancer information avoidance. In International Conference on Information (pp. 498-508). New York, NY: Springer, Cham. http://dx.doi.org/10.1007/978-3-319-78105-1_54

National Network of Libraries of Medicine (NN/LM). (n.d.). Health literacy. Retrieved from https://nnlm.gov/initiatives/topics/health-literacy

Nieto, S. (2010). Forward. In T. K. Chapman \& N. Hobbel (Eds.), Social justice pedagogy across the curriculum: The practice of freedom (pp. ix-x). New York, NY: Routledge.

Nussbaum, M. C. (2000). Women and human development: The capabilities approach. New York, NY: Cambridge University Press.

Olshansky, S. J., Antonucci, T., Berkman, L., Binstock, R. H., Boersch-Supan, A., Cacioppo, J., ... \& Rowe, J. (2012). Differences in life expectancy due to race and educational differences are widening and may not catch up. Health Affairs, 31(8), 1803-1813. https://doi.org/10.1377/hlthaff.2011.0746

Ratzan, S. C., \& Parker, R. M. (2000). Introduction. In C. R. Selden, M. Zorn, S. C. Ratzan, \& R. M. Parker (Eds.), National Library of Medicine current bibliographies in medicine: Health literacy. NLM Pub. No. CBM 2000-1. Bethesda, MD: National Institutes of Health, U.S. Department of Health and Human Services.

Ruger, J. P. (2004). Health and social justice. The Lancet, 364(9439), 1075-1080. https://dx.doi.org/10.1016\%2FS0140-6736(04)17064-5

The International Journal of Information, Diversity, \& Inclusion, 3(3), 2019

ISSN 2574-3430, jps.library.utoronto.ca/index.php/ijidi/index

DOI: $10.33137 /$ ijidi.v3i3.32961 
Ruger, J. P. (2006a). Health, capability, and justice: Toward a new paradigm of health ethics, policy and law. Cornell Journal of Law \& Public Policy, 15(2), 403-482.

Ruger, J. P. (2006b). Toward a theory of a right to health: Capability and incompletely theorized agreements. Yale Journal of Law \& the Humanities, 18(2), 3.

Schillinger, D., Grumach, K., Piette, J., Wang, F., Osmond, D., Daher, C., Palacios, J., Diaz Sullivan, G., \& Bindman, A. B. (2002). Association of health literacy with diabetes outcomes. Journal of the American Medical Association, 288(4), 475-482. https://doi.org/10.1001/jama.288.4.475

Sen, A. (1993). Capability and well-being. In M. C. Nussbaum \& A. Sen (Eds.), The quality of life (pp. 30-66). New York, NY: Oxford University Press.

Sensoy, O., \& DiAngelo, R. (2012). Is everyone really equal?: An introduction to key concepts in social justice education. New York, NY: Teachers College Press.

St. Jean, B., Jindal, G., \& Liao, Y. (2017). Is ignorance really bliss?: Exploring the interrelationships among information avoidance, health literacy and health justice. Proceedings of the Association for Information Science and Technology, 54(1), 394-404. https://doi.org/10.1002/pra2.2017.14505401043

United Nations Committee on Economic, Social and Cultural Rights. (2000). Substantive issues arising in the implementation of the International Covenant on Economic, Social and Cultural Rights: General comment no. 14. The right to the highest attainable standard of health (article 12 of the International Covenant on Economic, Social and Cultural Rights). Retrieved from https://tbinternet.ohchr.org/_layouts/treatybodyexternal/Download.aspx?symbolno=E \%2fC.12\%2f2000\%2f4\&Lang=en

Venkatapuram, S. (2011). Health justice: An argument from the capabilities approach. Malden, MA: Polity Press.

Weiss, B. D. (2007). Health literacy and patient safety: Help patients understand (2nd ed.). American Medical Association Foundation and American Medical Association. Retrieved from

https: //web.archive.org/web/20180414201755/https://med.fsu.edu/userFiles/file/ah ec_health_clinicians_manual.pdf

World Health Organization (WHO). (1946). Constitution of the World Health Organization. Retrieved from http://apps.who.int/gb/bd/PDF/bd47/EN/constitution-en.pdf?ua=1

World Health Organization (WHO). (2011). Closing the gap: Policy into practice on social determinants of health. World Conference on Social Determinants of Health, Rio De Janeiro, Brazil, October 19-21, 2011. Retrieved from https://www.who.int/sdhconference/Discussion-Paper-EN.pdf

World Health Organization (WHO). (2017). Human rights and health. Retrieved from https://www.who.int/news-room/fact-sheets/detail/human-rights-and-health

The International Journal of Information, Diversity, \& Inclusion, 3(3), 2019

ISSN 2574-3430, jps.library.utoronto.ca/index.php/ijidi/index

DOI: $10.33137 /$ ijidi.v3i3.32961 
Beth St. Jean (bstjean@umd.edu) is an Associate Professor in the College of Information Studies at the University of Maryland, College Park, USA. She is also the Assistant Director of the Information Policy and Access Center (iPAC) and an affiliate faculty member of the Horowitz Center for Health Literacy (http://sph.umd.edu/center/hchl). Dr. St. Jean's research aims to improve people's long-term health outlooks by exploring the important interrelationships between their health-related information behaviors, health literacy, health-related selfefficacy, and health behaviors. She has worked with both adults and children over the past several years. In collaboration with her colleague, Dr. Mega Subramaniam, Dr. St. Jean codeveloped the NLM-funded HackHealth after-school program (http://hackhealth.umd.edu/) to help improve disadvantaged middle school students' health-related self-efficacy and their digital health literacy skills. Dr. St. Jean's most recent research focuses on the concept of health justice, particularly aiming to identify the information-related causes of, and potential solutions to, health disparities.

Gagan Jindal (gjindal@umd.edu) is a doctoral candidate in the College of Information Studies at the University of Maryland, College Park, USA. Her research interests include the information behaviors of people who have chronic illnesses, how patients connect offline using new and existing technologies, and other related areas of consumer health informatics. Prior to joining the iSchool, Gagan worked as a Research Analyst in the health informatics division at NORC at the University of Chicago in Bethesda, Maryland and as a Program Associate for a mobile health start-up, Vibrent Health, in Fairfax, Virginia. She holds a Master of Public Health with a concentration in Global and Community Health from the George Mason University, Fairfax Virginia.

Yuting Liao (ylia0598@umd.edu) is a Ph.D. candidate in Information Studies at the University of Maryland, College Park. She leverages both quantitative and qualitative methods to explore human experiences interacting with social technology. Her studies focus on the issue of privacy and how people make information disclosure decisions in various socio-technical contexts, from fitness trackers to conversational Al to online social networks, with the goal of inspiring technology design to improve service and experiences in the healthcare domain. Yuting holds a Master's degree in Communication, Culture \& Technology from Georgetown University and a Bachelor's degree in Journalism and Communication from the Renmin University of China.

Paul T. Jaeger (pjaeger@umd.edu) is Professor, Diversity \& Inclusion Officer, and Co-Director of the Master of Library and Information Science (MLIS) program of the College of Information Studies, as well as Co-Director of the Information Policy and Access Center (iPAC) at the University of Maryland. He is the author of more than one hundred and eighty journal articles and book chapters, along with sixteen books. Dr. Jaeger is Co-Editor of Library Quarterly, Editor of Advances in Librarianship, and Associate Editor of the International Journal of Information, Diversity, \& Inclusion. He is the founder of the Conference on Inclusion and Diversity in Library and Information Science (CIDLIS) and is the co-founder of the UMD Disability Summit. In 2014, he received the Library Journal/ALISE Excellence in Teaching Award.

The International Journal of Information, Diversity, \& Inclusion, 3(3), 2019

ISSN 2574-3430, jps.library.utoronto.ca/index.php/ijidi/index

DOI: $10.33137 /$ ijidi.v3i3.32961 